\title{
A EXPERIÊNCIA DO ALUNO DO 6 ANO DO ENSINO FUNDAMENTAL II PARA A LEITURA DO TEXTO LITERÁRIO
}

\author{
W. C. COSTA* e C. BOTELHO \\ Universidade de Pernambuco - Campus Mata Norte \\ waltercavalcanticosta@gmail.com* \\ Artigo submetido em março/2015 e aceito em dezembro/2015 \\ DOI: $10.15628 /$ holos.2015.2829
}

\section{RESUMO}

O texto literário é uma fonte inesgotável de experiência estética. Para desenvolver o prazer da leitura, bem como a formação do leitor competente, é preciso valorizar a forma de mediar a leitura, pois a literatura é mais que o gozo, é um direito, é um exercício de cidadania. Este artigo tem como base as ideias dos teóricos da educação Kefalás (2012), Yunes; Oswald (2013), Larrosa (2011),
Cosson (2011) e apresenta os resultados de um projeto experimental de letramento literário com o livro de literatura infantil "A batalha dos mamulengos", do escritor Rubem Rocha Filho, em uma turma do sexto ano do ensino fundamental, de uma escola pública, do estado de Pernambuco, realizado entre agosto e setembro de 2014.

PALAVRAS-CHAVE: Educação, Letramento Literário, Experiência Literária, Ensino Fundamental.

\section{TEXT READING LITERARY EXPERIENCE FOR ELEMENTARY SCHOOL}

\begin{abstract}
The literary text is an inexhaustible source of aesthetic experience. To improve the pleasure of reading, and the training of competent reader, we need to enhance the way of mediating reading, because literature is more than enjoyment, is a right, it is an exercise of citizenship. Based on the work of education theorists Kefalas (2012), Yunes \& Oswald (2013), Larrosa (2011), Cosson (2011), this
\end{abstract}

work is the result of an experimental project of Literary Literacy through children's literature book "The Battle of Mamulengos", by the writer Rubem Rocha Filho, in a class of sixth year of elementary education, at a public school, in the state of Pernambuco, between August and September 2014.

KEYWORDS: Education, Literacy Literary, Literary Experience, Elementary School. 


\section{INTRODUÇÃO}

O presente artigo visa relatar o processo de fomentação e aplicação de um trabalho com o livro "A batalha dos mamulengos", do escritor Rubem Rocha Filho, e com ilustrações de André Neves, numa turma do 60 ano do ensino fundamental, da Escola Professora Olindina Alves Semente, em Recife-PE. Para isso, foi criada uma ficha de leitura visando avaliar como os alunos conseguem absorver o livro literário em três competências: Identificação das características técnicas e origens do livro; reconhecimento das etapas do livro e formação do senso crítico do leitor; estímulo à criatividade a partir da linguagem não verbal.

Neste trabalho, a leitura do texto literário é vista não como um suporte para o aprendizado de Língua Portuguesa, prática criticada por vários autores da área, mas como um objeto motivador de sensações, de experiências artísticas, finalmente como justificativa para o ser no mundo, além de ter finalidade gratuita e de produzir deleite e catarse. Os currículos escolares, de certo modo, negam aos alunos o direito a esseselementos, pois na maioria das vezes, privilegiam não o textoescritura, fonte de suspensão da realidade da criação de senso artístico, como alerta Kefalás (2012). Daí a importância do relato desta prática realizada na tentativa de fomentar o letramento literário, desenvolvido por Cosson (2011), de divulgar o processo e os resultados alcançados como contribuições à discussão da necessidade de introdução do estudo do texto literário, ainda no ensino fundamental.

\section{LETRAMENTO LITERÁRIO}

O letramento literário é um processo de formação de leitores literários, realizado com base na experiência da leitura de textos artísticos, isto é, que têm por função promover o prazer estético, através da valorização das experiências anteriores do receptor.

A significação, o despertar dos sentidos, o ganho de vida, a corporeidade de um texto só se presentificam através da leitura. À leitura textual literária sucede uma leitura muito maior, que é a leitura de mundo. Apenas quem lê o mundo consegue ler um texto de forma satisfatória, pois a literatura, ainda que seja um ato gratuito, resulta das vivências sociais tanto do autor, como do receptor.

Assim, segundo Jauss, a recepção, ou seja, a atividade leitora, entendida como ato de "concretização do sentido como duplo horizonte", (JAUSS, 1979, p. 50) aquele suscitado pela obra, que resulta da visão de mundo do seu criador, mas também das experiências do leitor, esse último concebido como coautor, uma vez que o texto literário, só se concretiza a partir de suas várias e diferentes recepções.

Desse modo, a proposta de letramento literário de Cosson tem como ponto de partida a Estética da Recepção, no que respeita à relação existente entre o mundo da criação artística e de sua recepção.

Cosson (2011) estabelece para realização do letramento literário duas sequências a básica e a estendida. A primeira delas, aplicada na experiência apresentada neste artigo, composta por quatro etapas motivação, introdução, leitura e interpretação. Na motivação acontece a introdução do tema do texto literário de forma dinâmica, criativa, indireta e instigante. Na introdução, há uma 
apresentação do autor e da obra. Durante a leitura, há um processo composto por vários mecanismos.

Para especificar melhor tais mecanismos, escolhemos o processo de leitura, ponderado por Dell'Isola (2001, p. 107), que é composto por decodificação, compreensão, inferenciação, avaliação e retenção na memória. Para a interpretação, há uma problematização de discussões provocadas pelo texto e um entendimento mais apurado do que aquele tipo de literatura quer comunicar.

Para Cosson (2011, p. 56, 57), o elemento lúdico ajuda a aprofundar a leitura da obra literária. Entretanto esse elemento lúdico não pode conduzir a leitura literária, sob risco de minimizar a interpretação do aluno, uma vez que valoriza a interpretação do professor. Sendo assim, é preciso observar que a didatização da literatura é um caminho usado por professores para ensinar literatura, reconhecendo-se que influências existem em qualquer processo de leitura, mas com o objetivo de legitimar a literatura enquanto disciplina escolar.

Ao falar da introdução da compreensão da obra literária, Cosson $(2011$, p. 58, 59) comenta um processo de formação de leitores literários que realizou com alunos de um pré-vestibular. Na ocasião, houve o benefício de conhecer autores e obras pré-selecionadas, mas de modo tão espontâneo a ponto de uma aluna chegar a achar ter escolhido o texto literário, mesmo não sendo, pois tamanha foi a sua identificação com o mesmo com o seu horizonte de expectativas. Também salientou que a leitura não havia sido imposta, mas construída com um maior grau de liberdade.

Para realização da introdução necessita-se de alguns cuidados, tais como: não expor de forma longa a obra do autor, assegurar o processo pedagógico da leitura, para não desviar do foco ou esperar que o texto fale por si só, apresentar o livro físico aos alunos. Nesta ocasião, devem ser apresentados os componentes paratextuais da obra: a capa, a orelha, contracapa e prefácio, todos vistos como instrumentos geradores de expectativas sobre o texto que deve ser lido em seguida.

O processo de leitura é regido por estratégias como leitura silenciosa, leitura do professor em voz alta, leitura do aluno em voz alta, poema musicalizado, leitura em coro, audição do poema recitado pelo próprio poeta e leitura coletiva repetindo com o professor. Essas são apenas algumas das várias formas possíveis de leituras realizadas na experiência aqui relatadas. Cosson (2011) não preconiza formas de realização e aplicação da sequência básica, em vista de considerar ser imprescindível garantir a percepção e criatividade do docente, que deve ser determinada por situações condizentes com o estímulo à participação e à valorização do universo de experiência do leitor.

Para a interpretação admite dois momentos, um interior, e outro exterior. No momento interior, há a decifração das palavras, frases, enunciados e seus labirintos, como no processo de leitura proposto do Dell'Isola (2001), e um exterior, com a concretização e materialização de sentidos baseado na comunidade onde o leitor está inserido. No processo de leitura, "a interpretação parte do entretecimento dos enunciados que constituem as inferências, para chegar à construção do sentido do texto, dentro de um diálogo que envolve autor, leitor e comunidade" (COSSON, 2011, p.64). 


\section{A LITERATURA PARA ALUNOS (AS) DO 60 ANO DO ENSINO FUNDAMENTAL NAS ESCOLAS PÚBLICAS DO ESTADO DE PERNAMBUCO}

No Estado de Pernambuco, dos documentos que regem o ensino de Língua Portuguesa, podem-se destacar os três mais atualizados: o Currículo de Português para o Ensino Fundamental (PERNAMBUCO, 2012a), os Parâmetros Curriculares de Língua Portuguesa-PCLP (PERNAMBUCO, 2012b), e os Parâmetros na Sala de Aula - PSA (PERNAMBUCO, 2013).

O primeiro traz, de forma objetiva, os conteúdos divididos por turma e por unidade. É uma versão mais prática, simplificada e objetiva do segundo, com a finalidade principal de servir como base de preenchimento de cadernetas. $O$ segundo são as expectativas de aprendizagem e uma fundamentação teórica sólida. O terceiro aborda planos de aula e sugestões de ensino para cada turma. Não contempla todos os conteúdos, mas traz os mais recorrentes.

Sobre os Parâmetros para a Educação Básica do Estado de Pernambuco, é possível observar que os mesmos tratam das principais orientações para o ensino básico e apresentam-se em duas vertentes: a primeira chamada de "Parâmetros Curriculares" e a segunda de Parâmetros na Sala de Aula.

A primeira (PERNAMBUCO, 2012b), posta um considerável avanço em relação às OTM (PERNAMBUCO, 2008), principalmente por modificar os eixos orientadores, objetivando: a produção e compreensão de textos orais; a leitura e compreensão de textos; produção de textos escritos; análise linguística e reflexão sobre a língua. Quanto ao ensino da Literatura, valoriza expectativas de aprendizagem com outros eixos, tais como: apropriação do Sistema Alfabético; análise linguística; oralidade; leitura; letramento literário; escrita.

A segunda vertente (PERNAMBUCO, 2013) trata de diferentes sugestões de ensino. Interessante que traz um dos poemas selecionado para realização de uma das oficinas proposta neste projeto, trata-se do poema "Rosa de Hiroshima", de Vinicius de Moraes. Nos PSA (PERNAMBUCO, 2013, p. 81-84), há um plano de aula para o poema em destaque.

Orienta também para a necessidade de "desenvolvimento de um trabalho sistemático" de domínio de habilidades e conhecimentos mais complexos, relevantes à formação do leitor de poemas, entretanto, este é destinado aos alunos de 7으 ao 9 ㅇ ano, do ensino fundamental, uma vez que "estão relacionados à capacidade de atribuir sentidos a recursos da linguagem figurada, bem como a outros recursos de significação e estéticos" (PERNAMBUCO, 2013, p. 81). Por isso, os alunos do sexto ano ainda não estariam preparados para entender um poema de tal complexidade.

É mister a ciência de exigências bem mais esdrúxulas para a realidade de ensino público nos parâmetros do Estado, do que uma interpretação poética de qualidade para o 60 ano do ensino fundamental, a exemplo de quantidade de gêneros textuais solicitados para serem trabalhados pelo professor, de acordo com Parâmetros Curriculares de Língua Portuguesa - PCLP (PERNAMBUCO, 2012b).

Há abordagem de dezesseis gêneros textuais só no eixo "oralidade", para a quarta unidade, e nenhum desses gêneros são considerados como literários em sua essência, o que mostra um predomínio da perspectiva linguística e tecnocrata no estudo de língua e linguagens. Abaixo segue a lista: "relatos de experiência, depoimentos, notícias, reportagens, seminário, palestra, apresentação de livros lidos, entrevistas, debates, propagandas, respostas a questões, 
Justificativas, defesa de ponto de vista, avisos, mesas-redondas e apresentações orais de seminários" (PERNAMBUCO, 2012b, p. 60-62).

A listagem expressa revela, sem sombra de dúvida, a inexistência da proposta de trabalho pedagógico com gêneros textuais literários. Saliente-se também que quanto ao componente "apresentação de livros lidos", não há nenhuma observação sobre o gênero textual dos textos que compõem os livros a serem apresentados, daí poder-se inferir pela omissão de referência a essa questão, que os referidos livros podem ser literários ou não.

Apesar dos esforços para normatizar e recomendar uma educação de qualidade, todos os três documentos enfatizam o aspecto técnico da língua, mas não dá o mesmo destaque para a literatura. Para o ensino fundamental, não há uma disciplina específica, mas um plano de trabalho para o letramento literário que apresenta algumas lacunas e mostra-se muito mais superficial que os outros eixos do currículo.

A superficialidade do eixo do currículo sobre o letramento literário precisa ser repensada nas próximas edições dos documentos norteadores da área de linguagem. Literatura é cultura e refletir sobre a cultura, como algo que permeia a realidade, é um ato de extrema necessidade. 0 grande problema, na atualidade, é a mercantilização desta, isto é, o fato de se encarar a arte e a cultura como mercadoria, como objeto de consumo. Souza (2008) discorre sobre o assunto de forma concisa no trecho:

\begin{abstract}
O fenômeno da cultura também se organizou como objeto de troca e venda, num mundo em que a mercadoria gera mais mercadoria e até o sonho virou peça mercantilizada. Esta é a forma por excelência neoliberal de tratar a arte e as manifestações culturais que têm no excesso de informação na cidade e na mídia seu contraponto e complemento (SOUZA, 2008, p. 18).
\end{abstract}

A forma como a cultura, como a arte, como a literatura chega até aos alunos é uma preocupação que deve ser de todos os docentes, não apenas da área de literatura.

Por outro lado, Dias (2011, p. 160) defende o ensino de literatura em sala de aula em conjunto com outras formas de linguagens, seja verbal ou não verbal, incluindo uso de recursos tecnológicos. Essa iniciativa não deve ser encarada como um modismo, mas como adequação ao período histórico atual: é preciso perceber a literatura como linguagem que deve integrar-se à vida das crianças e jovens, tornar-se um hábito, uma experiência frequente.

Como já foi dito anteriormente, este trabalho se constitui como proposta de intervenção, através de um estudo de caso, criar um projeto piloto/experimental de letramento literário, que valorize a experiência do aluno-leitor. Foi aplicada no sexto ano do ensino fundamental série que possui uma característica peculiar: os alunos são recém-saídos do ensino fundamental séries iniciais e estranham a quantidade de disciplinas. Situam-se no limiar entre a infância e a adolescência e desejosos de novas descobertas a serem feitas, razão pela qual não se pode esquecer que estão em uma fase do desenvolvimento humano na qual a leitura do texto literário pode responder-Ihes a algumas questões.

Conscientes das questões levantadas, iniciamos os alunos do 60 ano do ensino fundamental de uma escola publica do Estado de Pernambuco, no prazeroso ato da leitura, realizando uma prática de letramento literário que os motivasse, pois acreditamos no papel humanizador e na valorização da literatura, concordando com o que afirma Candido (2001, p.176): “[...] a literatura 
aparece claramente como manifestação universal de todos os homens em todos os tempos. Não há povo e não há homem que possa viver sem ela."

Considerando a literatura uma necessidade humana, podemos deduzir que não é possível haver alguém que resista a um trabalho motivador com o texto literário. Assim, o que prejudica a aceitação e a formação do leitor literário é a ausência do emprego de estratégias que conduzam à motivação, aguçando a curiosidade dos mesmos e promovendo a vivência estética da arte literária.

\section{O TEXTO LITERÁRIO COMO EXPERIÊNCIA ESTÉTICA DA ARTE}

Nessa perspectiva, reconhecemos que a experiência apresenta várias dimensões. Larrosa (2011) aborda algumas delas: "exterioridade", "reflexividade", "passagem" e "paixão". A primeira diz respeito à tomada de conhecimento da realidade à volta do sujeito, já a segunda relaciona-se ao "eu" do sujeito em contato com a experiência e a terceira refere-se ao prazer, à fruição da arte.

A experiência é "isso que me passa". Vamos agora com esse passar. A experiência, em primeiro lugar, é um passo, uma passagem, um percurso. Se a palavra experiência tem o ex de exterior, tem também esse per que é um radical indoeuropeu para palavras que tem que ver com travessia, com passagem, com caminho, com viagem. A experiência supõe, portanto, uma saída de si para outra coisa, um passo para outra coisa, para esse ex de que falamos antes, para esse isso de "isso que me passa". Mas, ao mesmo tempo, a experiência supõe também que algo passa desde o acontecimento para mim, que algo me vem ou me advém (LARROSA, 2011, p. 8).

Freire (2011), destaca a importância da leitura, ao ressaltar a re-criação, a re-vivência do mundo, a leitura, o entendimento daquilo que cerca o sujeito. A forma de como se lê é de fundamental importância na formação do sujeito.

Já Kefalás (2012) admite que a palavra, o texto literário como escritura, é uma fonte de prazer e de experimentações que foge da concepção informativa de leitura. $O$ texto-escritura é encarado como arte. A autora ressalta ainda que é um direito, e não um favor, o ensino de literatura. Ela critica o "regime político da exceção", em que o texto literário por ser considerado "mais difícil" e "menos útil", aparece retalhado, mutilado em livros didáticos e não tem a sua acessibilidade e incentivo garantidos.

Para incentivar a leitura de textos-escrituras, Kefalás (2012) enfatiza o uso do texto literário, seja em leituras individuais seja em leituras em voz alta, cujo reconhecimento do ritmo das palavras e os aspectos sensoriais são elementos que tornam a leitura prazerosa.

Na perspectiva mnemônica, Halbwachs (2006) afirma que o ser não é apenas um indivíduo: é um indivíduo dentro de um contexto social, influenciando e sendo influenciado por ele. Assim, dentro do contexto deste trabalho, o aluno pode ser visto como integrante de um contexto maior:

Nossas lembranças permanecem coletivas e nos são lembradas por outros, ainda que se trate de eventos em que somente nós estivemos envolvidos e objetos que só nós vimos. Isto acontece porque jamais estamos sós. Não é preciso que outros estejam presentes, materialmente distintos de nós, porque sempre levamos conosco e em nós certa quantidade de pessoas que não se confundem (HALBWACHS: 2006, p. 30). 
A literatura é como os indivíduos em Halbwachs (2006), é invidividual e coletiva ao mesmo tempo. É individual, pois é fruto da criação de um autor; é coletiva, por trazer em si traços culturais de alteridade, por ser uma representação criativa não só de si, mas do outro e do mundo. Enxergar a literatura enquanto a experiência estética é ver o indivíduo como um ser social.

\title{
5 METODOLOGIA
}

O presente trabalho resultante de uma pesquisa qualitativa, tendo por método o estudo de caso, por buscar entender o aluno como um ser influenciado pelo seu meio. No que concerne a compreensão do método e do tipo de pesquisa tomamos como embasamento os trabalhos de Alves-Mazzotti (2006) e Meirinhos e Osório (2010).

Não foi escolhida a metodologia quantitativa, como método experimental ou hipotéticodedutivo, por conta de não haver um distanciamento entre o investigador e realidade estudada. Há uma preocupação social, uma vez que os alunos do 60 ano do ensino fundamental são de uma escola pública estadual pernambucana de difícil acesso, localizada no bairro do Barro, em RecifePE.

A maioria dos alunos é do próprio bairro e não tem condições financeiras abastardas e muitos vão para a escola descalços e o pior: não acreditam em seu próprio potencial. São marginalizados pela sociedade, mas merecem o direito de ter uma condição social mais confortável no presente e no futuro. Para isso, o reconhecimento das dificuldades extraclasse e extra escola beneficiaram o direcionamento desse projeto, piloto/experimental de letramento literário, visando a formação e consolidação de uma competência primordial para todos, a leitura do texto literário.

O estudo de caso tem uma característica diferencial no que diz respeito a projeto de investigação, uma vez que não há uma metodologia pré-estabelecida, não são previamente sistematizados. A sistematização ocorre conforme a análise do caso. Além disso, é holístico, uma vez que visa encontrar um padrão no meio dos casos, entender o global em vez de analisar os fenômenos. Para isso, houve preocupação com o entendimento do contexto dos analisados. Ao falar sobre o papel do investigador nos estudos de caso, Meirinhos e Osório (2010, p. 60) afirmam:

\begin{abstract}
Este aspecto transporta-nos para a relação sujeito/objecto na investigação. As abordagens positivistas criaram a ideia do observador neutro, sem influência sobre o objecto de investigação. Neste sentido, pode-se captar uma realidade objectiva, na medida em que se considera que pode ser eliminada a subjectividade através de uma relação distante do observador/investigador. As posições opostas, anteriormente referidas, sustentam que o investigador se implica a nível relacional com o objecto de investigação. Estas posições admitem a existência de um papel mais construtivo do sujeito e, consequentemente, a existência de uma realidade subjetiva.
\end{abstract}

A intenção, com esta metodologia, foi fazer um trabalho piloto/experimental de letramento literário que visasse à experiência do aluno de forma que se realizasse uma série de intervenções leitoras que possibilitasse a formação do aluno como leitor.

Tais mudanças não significaram o abandono do objetivo inicial, que era o de avaliar o nível de leitura e ajudar a estimular a prática leitura literária, mas uma readequação ao contexto para 
garantir a validade do proposto. Este posicionamento é essencial para não se cair no lugar comum "funcionando apenas na teoria". Uma vez que este trabalho foi piloto/experimental, foi possível pressupor que se trata de um estudo de caso único, por intentar o estímulo de criação de outros casos semelhantes.

Seguimos a Meirinhos e Osório (2010, p. 641, 642) quando que:

No estudo de caso instrumental, ao contrário, o interesse no caso deve-se à crença de que ele poderá facilitar a compreensão de algo mais amplo, uma vez que pode servir para fornecer insights sobre um assunto ou para contestar uma generalização amplamente aceita, apresentando um caso que nela não se encaixa.

O tipo de estudo foi o explanatório único e holístico de caso único, por visar o estabelecimento de causa-efeito, visando ser para referência de estudos futuros na área.

\subsection{Sobre a elaboração da ficha}

A ficha foi criada com a finalidade de avaliar três competências: 1 . Reconhecimento das características técnicas e origens do livro (questões de 1 a 5 e questão 9): "Título, autor, obra, editora, cidade e ano de publicação, diferença entre poesia e prosa". 2. Reconhecimento das etapas do livro e formação do senso crítico do leitor (questões 6 a 8): "Resumo, transcrição do trecho mais marcante do livro e justificativa, julgamento sobre a qualidade do livro". 3. Estímulo à criatividade a partir da linguagem não verbal: "Recriação através de desenho da capa do livro com base na leitura".

Após a elaboração e aplicação da ficha, bem como após o processo de produção deste capítulo, outras possíveis questões para uma próxima ficha surgiram. Duas destas apresentam pertinência para uma possível continuação: 1 . Pergunta sobre um acontecimento específico do livro. 2. Elaboração de um final diferente para o livro. Por conta do espaço na ficha, as duas questões ficaram para servirem de aspectos diferenciais no andamento da próxima experiência, uma vez que se trata de um componente de uma experiência piloto.

\subsection{Sobre o livro escolhido}

O livro A batalha dos mamulengos, do autor Rubem Rocha Filho, e do ilustrador André Neves, atendeu aos seguintes critérios:

1. Autor carioca, mas com fortes influências da cultura do Estado de Pernambuco, como a presença na narrativa da arquitetura e dos monumentos históricos.

2. A história passeia por pontos turísticos do estado de Pernambuco em Recife, Olinda, Jaboatão, Itamacará e Caruaru.

3. Linguagem acessível, adequada para a turma em questão.

4. Ilustrações coloridas.

5. É um romance com cento e onze páginas, gênero literário muitas vezes que assusta os alunos. 


\section{RESULTADOS OBTIDOS NA APLICAÇÃO DA FICHA DE LEITURA}

\subsection{Adesão da turma}

A Escola Professora Olindina Alves Semente é uma escola pública estatual localizada no bairro do Barro, em Recife-PE. O turno da manhã possui três sextos anos e a turma do 60 ano A, com trinta e seis alunos em 2014, foi escolhida por ter sido contemplada com a leitura de um livro literário padrão. Os dois outros sextos anos não foram escolhidos, pois não tiveram livros diferentes, além de uma adesão menor ainda.

Uma aluna entregou a ficha depois do prazo de um mês, entre agosto e setembro de 2014, e fez sobre outro livro, por isso não entrou no recorte de análise aqui proposto, mas apenas no gráfico que será mostrado abaixo para efeito de comparação entre o total de alunos e as fichas entregues.

\section{Fichas entregues/fichas não entregues}

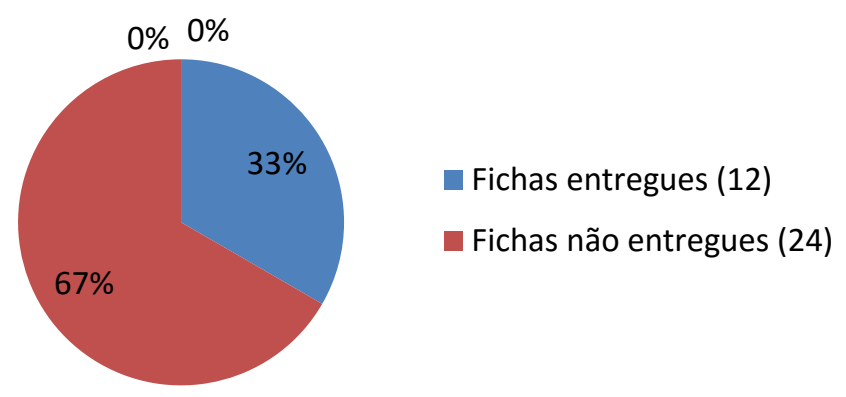

Demonstração da proporção de fichas entregues em relação às fichas não entregues.

Chama atenção a predominância de fichas não entregues, pois dos trinta e seis alunos matriculados na turma em questão, apenas doze entregaram a ficha de leitura, mesmo com mais de um mês entre o período da entrega do livro e a realização de uma discussão introdutória. Ao debate seguiu-se a apresentação do vídeo The "Fantastic Flying Books of Mr Morris Lessmore", produzidos em animação computadorizada, vencedor do Oscar 2011, como melhor curta metragem de animação. O título pode ser traduzido como Os fantásticos livros voadores do Sr. Morris Lessmore e trata de como a vida das pessoas se modificam quando estão envolvidas pela leitura. Os personagens não utilizam palavras e o vídeo é regido pelas cores e pelos sons das músicas e dos objetos, o lúdico é reforçado ainda por livros voadores reprodutores de comportamentos da personalidade humana.

Entendeu-se, de acordo com o que apresenta o gráfico, que os possíveis motivos ou causas para um número maior de alunos não terem participado maciçamente, foram a ausência da cultura leitora na família, de vivências leitoras anteriores e a resistência a novas experiências.

\subsection{Análise dos dados obtidos com os questionários}

Quanto à primeira competência Reconhecimento das características técnicas e origens do livro, foi realizada pelos alunos com sucesso. Dez dos onze alunos conseguiram obter todos os aspectos que envolvem a leitura informativa do livro, de reconhecer e classificar dados, bem como de pesquisar a origem do autor do livro. $O$ grande destaque foi que todos conseguiram identificar 
que o livro pertence à área da prosa e não da poesia. Dois conteúdos trabalhados em sala de aula no bimestre anterior.

A segunda competência, Reconhecimento das etapas do livro e formação do senso crítico do leitor, apresentou também bons resultados, uma vez que os alunos nos resumos conseguiram, em sua maioria, sumarizar com as próprias palavras os acontecimentos do livro. Além disso, na questão que pedia o trecho mais marcante, a escolha de cada um foi motivada pela experiência de vida e pelo fator identidade. O mesmo ocorreu com as considerações sobre a qualidade do livro. O Conceito de como o reconhecimento dos aspectos ligados à terra natal e o papel catártico da leitura, além do fato do leitor sentir-se integrado à mesma, também se fez notório.

Já a terceira competência "Estímulo da criatividade a partir da linguagem não verbal" estimulou o aspecto lúdico-visual da leitura, os alunos optaram ou tentaram reproduzir imagens do próprio livro, criar suas próprias interpretações gráficas, o que não deixa de ser um exercício de criticidade, compreensão e criatividade.

As respostas vieram comprovar a necessidade de se desenvolver um plano direcionado para o letramento literário. Em síntese os resultados alcançados nos fazem acatar a afirmação Yunes (in YUNES; OSWALD, 2003), para quem ler:

[...] é desfazer a certeza dura e vacilar com a confiança de que se perdendo há mais a encontrar: a linguagem não se esgota no sentido atribuído historicamente, suspenso sobre seu uso cotidiano. Não é à toa o recurso da alegoria, à parábola, à poesia para driblar o endurecimento dos discursos. As palavras vivem entre os homens e a ninguém pertencem com exclusividade (YUNES IN YUNES; OSWALD, 2003, p. 10).

Ora as palavras de Yunes traduzem perfeitamente nossas expetativas, tendo em vista que concordamos com o fato de que cada leitura corresponde a um ato de atribuição de novos sentidos à leitura, portanto cada leitor é uma espécie de recriador da obra, dado que lhe impõe um novo sentido.

\section{CONSIDERAÇÕES FINAIS}

Os currículos escolares do estado de Pernambuco necessitam de uma mudança visando respeitar o direito que os alunos têm ao texto literário. Não há um plano para a literatura em nenhum dos três documentos que norteiam o ensino de escolas públicas estaduais. Os benefícios da prática leitora são tantos que são suficientes para que as autoridades repensem os currículos.

A experiência do texto literário está atrelada a histórias de vidas leitoras, daí a formação do leitor que relatada, como o primeiro passo, foi de fundamental importância, despertar o leitor existe em cada pessoa, para que os seres humanos em especial, sejam despertados para importância da leitura.

A consciência de que a leitura de texto literário deve ser preservada e estimulada no nível de Ensino Fundamental nos propiciou o desejo de criar uma alternativa, ainda que muito elementar, de acordo com as três competências, anteriormente colocadas, elaboradas com base nos teóricos que integram as referências. 
O relato da experiência apresentada neste artigo está longe de ser o ideal, mas é, antes de tudo, uma tentativa e, como boa parte das tentativas, precisa ser melhorada, aperfeiçoada, não apenas teoricamente, mas na prática, com ênfase no público leitor em questão. O problema da baixa adesão espontânea dos alunos é preocupante, mas são suficientes para darmos continuidade a esta iniciativa.

Assim, desejamos que o presente relato consiga atingir seu objetivo propedêutico: contribuir para a prática pedagógica e de incentivo à leitura, provocando possíveis mudanças e inovações na sala de aula.

\section{REFERÊNCIAS}

1. ALVES-MAZZOTTI, Alda Judith. Usos e abusos dos estudos de caso. Disponível em: Cadernos de Pesquisa, v. 36, n. 129, set./dez. 2006.

2. CANDIDO, Antonio. Vários escritos. Rio de Janeiro: Ouro sobre Azul, 2011.

3. COSSON, Rildo. Letramento literário: teoria e prática. São Paulo: Contexto, 2011.

4. DELL'ISOLA, Regina Lúcia Péret. Leitura: inferências e contexto sociocultural. Belo Horizonte: Formato Editorial, 2001.

5. DIAS, Maria Heloisa Martins. Apagando o quadro negro. São Paulo: Cultura Acadêmica, 2011.

6. FREIRE, Paulo. A importância do ato de ler: em três artigos que se completam. 51á ed. São Paulo: Cortez, 2011.

7. HALBWACHS, M. A memória coletiva. São Paulo: Centauro, 2006.

8. JAUSS, Hans Robert. A estética da recepção: colocações gerais. In: A literatura e o leitor. Rio de Janeiro: Paz e Terra, 1979.

9. JOYCE, William; OLDENBURG, Brandon. The Fantastic Flying Books of Mr. Morris Lessmore (DVD). Produzido por: Moonbot Studios LA, LLC.

10. KEFALÁS, Eliana. Corpo a corpo com o texto na formação do leitor literário. Campinas, SP: Autores associados, 2012.

11. LARROSA, Jorge. EXPERIÊNCIA E ALTERIDADE EM EDUCAÇÃO. In: Revista Reflexão e Ação, Santa Cruz do Sul, v.19, n2, jul./dez. 2011.

12. MEIRINHOS, Manuel; OSÓRIO, António. O estudo de caso como estratégia de investigação em educação. Disponível em: EDUSER: revista de educação, Vol 2(2), 2010.

13. PERNAMBUCO. Secretaria de Educação. Currículo de Português para o Ensino Fundamental. Governo do Estado de Pernambuco. Secretaria de Educação. Recife: SE. 2012a.

14. - Secretaria de Educação. Orientações Teórico-metodológicas, ensino fundamental. Língua Portuguesa 1으 ao 9o ano. Recife: SE. 2008.

15. - Secretaria de Educação. Parâmetros Curriculares de Língua Portuguesa para o Ensino Fundamental e Médio. Governo do Estado de Pernambuco. Secretaria de Educação. Recife: SE. 2012b.

16. . Secretaria de Educação. Parâmetros na Sala de Aula: Língua Portuguesa para o Ensino Fundamental e Médio. Governo do Estado de Pernambuco. Secretaria de 
Educação. Recife: SE. 2013.

17. ROCHA FILHO, Rubem. A batalha dos mamulengos. Ilust. André Neves. Recife: Ed. Bagaço: 1995.

18. SOUZA, Valmir de. Cultura e literatura: diálogos. São Paulo: Ed. Do Autor, 2008.

19. YUNES, Eliana; OSWALD, Maria Luiza (orgs.). A experiência da leitura. São Paulo: Loyola, 2003.

\section{APÊNDICE A}

A ficha de leitura utilizada continha os seguintes dados:

Aluno (a):

Turma: Data:

1. Título da obra:

2. Autor (a):

3. Editora:

4. Cidade e ano de publicação:

5. O livro que você leu é de:

a) __ Poesia __ Prosa

b) Por quê?

6. Faça um resumo do livro em 10 linhas.

7. Transcreva o trecho do livro que mais chamou a sua atenção. Em seguida, faça um comentário para justificar a sua escolha.

8. Você considera o livro que você leu bom ou ruim? Explique.

9. Faça uma pequena pesquisa, em papel A4 branco, sobre o autor (a) do livro que você leu e anexe a esta ficha.

10. Refaça a capa do livro que você leu usando sua criatividade, com base em sua leitura e anexe a esta ficha. 